\title{
Classification Method and Application of Rock Fracture Ability by Supercritical $\mathrm{CO}_{2}$ Blasting
}

\author{
Xiaohong Zhu, ${ }^{1}$ Jianhong Jia $\mathbb{D}^{2},{ }^{2}$ and Zhongwei Cai ${ }^{3}$ \\ ${ }^{1}$ Wuchang University of Technology, Wuhan, Hubei, 430223, China \\ ${ }^{2}$ Three Gorges Geotechnical Consultants Co., Ltd., Wuhan, Hubei, 430074, China \\ ${ }^{3}$ China International Water \& Electric Corporation, Beijing 100120, China \\ Correspondence should be addressed to Jianhong Jia; swc@cug.edu.cn
}

Received 28 May 2021; Revised 14 November 2021; Accepted 3 December 2021; Published 11 January 2022

Academic Editor: Bangbiao Wu

Copyright $(2022$ Xiaohong Zhu et al. This is an open access article distributed under the Creative Commons Attribution License, which permits unrestricted use, distribution, and reproduction in any medium, provided the original work is properly cited.

In order to study the fracture ability classification of rock mass under the cracking action of supercritical $\mathrm{CO}_{2}$ phase transition, based on the classification theory of rock mass in blasting engineering, an analytic hierarchy process (AHP)-entropy weight method (EWM) and the cloud model classification method for rock mass cracking under $\mathrm{CO}_{2}$ phase transformation are proposed. In this method, rock density, rock tensile strength, rock wave impedance, and rock mass integrity coefficient are used as the factors to determine the level of rock mass fracturing, and the evaluation index system of rock mass fracturing is established. Through this evaluation method, the rock mass in a reconstruction project section of Nyingchi, Tibet, is classified and evaluated. The results present that this new classification method of rock mass fracture ability uses AHP-EWM to carry out the weight distribution of the classification index. In addition, it is combined with the cloud model for the classification division, overcoming the traditional classification method fixed with appraisal pattern flaw. Therefore, it has validity and feasibility. According to the characteristics of fracture ability, the rock masses in the area to be rebuilt on the Tibet Highway are divided into grade II, grade III, and grade IV, which provides scientific guidance for the construction of the project.

\section{Introduction}

At present, blasting is still the most important means of rock crushing excavation in open pit mining and underground engineering construction. In traditional blasting engineering, vibration, shock wave, flying stone, and other hazards are inevitably caused. In addition, there are certain safety hazards when applied in coal seams with a high concentration of gas. In order to overcome the above shortcomings of blasting, it is necessary to actively develop gas blasting excavation technology with high safety as a supplementary means of blasting excavation. Gas explosion excavation technology is the most widely used $\mathrm{CO}_{2}$ phase change fracturing technology. This technology originated at the beginning of the last century and was initially used to increase the permeability and mining of coal seams in British coal mines [1]. Subsequently, it was widely used in coal mines in many countries [2]. Nowadays, $\mathrm{CO}_{2}$ phase change fracturing has once again attracted attention due to the advantages of rock-soil blasting and excavation in complex environments [3-5]. Wang et al. [6] studied the phase change fracturing process of liquid $\mathrm{CO}_{2}$ from theoretical analysis and numerical simulation, established a mathematical model of coal seam fracturing pressure, and analyzed the fracturing influence range. Li et al. [7] investigated a new liquid $\mathrm{CO}_{2}$ rock breaking technology through a series of field tests and successfully applied the technology to rock excavation at the construction site of a subway station. At present, in the research of $\mathrm{CO}_{2}$ phase change fracturing and rock breaking, in order to ensure efficient fracturing of the target rock mass, it is necessary to carry out the fracture grading evaluation for various target rock masses existing in different geological environments, which can help in the parameter design and crack scheme optimization.

Rock mass fracture ability refers to the difficulty of rock mass cracking under high pressure in the process of $\mathrm{CO}_{2}$ 
phase transformation. At present, there is no relevant classification evaluation standard for rock mass cracking in the $\mathrm{CO}_{2}$ of phase change fracturing and rock breaking at home and abroad. However, the explosive classification of rock mass corresponding to commonly used explosives such as emulsion explosives has formed a relatively complete system. The blastability classification methods of rock mass can be divided into two main categories. The first category uses a single comprehensive index such as rock Platts coefficient and rock explosive unit consumption for blastability classification [8-10]. However, rock blastability classification is a comprehensive classification, it is necessary to comprehensively consider multiple factors such as rock density, tensile strength, and rock integrity coefficient. Therefore, the effect of this single index evaluation method is not ideal. The second category uses soft mathematical calculation methods such as set pair analysis, neural network, cluster analysis, matter element extension method, and gray correlation analysis for comprehensive blastability classification [11-16]. Zhou et al. [17] proposed a multifactor index system of rock mass blastability consisting of density, wave impedance, uniaxial compressive strength, and uniaxial tensile strength. Based on the system engineering theory, an improved multidimensional blastability classification model was established. On the basis of gray correlation theory and entropy weight theory, Gao et al. [18] established a comprehensive evaluation model of tunnel collapse risk based on entropy weight and gray correlation degree. Furthermore, the grade of collapse risk of the tunnel was obtained combined with the correction coefficient of tunnel construction according to rainfall conditions. Tao et al. [19] created the evaluation model of rock mass blastability based on the principle of cluster analysis and applied it to the classification of rock mass blastability in practical engineering. Zheng et al. [20] built a rock burst prediction model based on the entropy weight gray correlation BP neural network and utilized the model to the rock burst prediction of a tunnel project. The prediction results obtained were in good agreement with the actual conditions, which verified the feasibility and effectiveness of the model in the rock burst prediction.

The above research provides guidance for the classification evaluation of rock mass under blasting load, but the proposed models still have limitations. Moreover, due to the obvious difference between $\mathrm{CO}_{2}$ phase change induced fracture rock and explosive blasting, the existing rock mass explosive classification method cannot be directly applied to the evaluation of rock mass fracture behavior under $\mathrm{CO}_{2}$ phase change induced fracture. Therefore, it is necessary to carry out the evaluation of rock mass fracture behavior under phase change induced fracture. On the basis of the theory and idea of explosive classification of rock mass and considering the characteristics of rock breaking caused by $\mathrm{CO}_{2}$ phase transformation, this paper proposes a rock mass fracture ability classification evaluation method based on AHP-EWM and the cloud model and evaluates the fracture ability of the rock mass of a reconstruction project in Milin County, Tibet. This method provides a reliable reference for the safe and effective construction of the project.

\section{Methodology}

2.1. $\mathrm{CO}_{2}$ Phase Change Fracturing Method. The $\mathrm{CO}_{2}$ phase change fracturing (liquid $\mathrm{CO}_{2}$ liquid-gas phase cracking) rock breaking method is to put the crack tube with liquid carbon dioxide as shown in Figure 1 into the hole of the required rock mass drilled in advance. In the process of $\mathrm{CO}_{2}$ phase change fracturing and rock breaking, a $\mathrm{CO}_{2}$ storage tank is first used to fill the liquid $\mathrm{CO}_{2}$ into the liquid storage tube of the fracturing tube, and then the heater is energized on the tube to generate heat so that the liquid $\mathrm{CO}_{2}$ in the tube absorbs heat into a supercritical state. The supercritical carbon dioxide absorbs heat and heats up, and the internal pressure of the liquid storage tube continues to rise. When the pressure in the tube exceeds the rated pressure of the rupture disc, the shearing piece will be instantly broken, and the supercritical $\mathrm{CO}_{2}$ will instantly relieve the pressure and expand and transform into high-pressure gas. At the same time, the high-pressure $\mathrm{CO}_{2}$ gas is instantly released from the explosion vent nozzle set on the discharge head to provide the energy required for deformation of the rock mass medium, thereby causing the rock mass medium to produce relative displacement and create cracks.

\subsection{Classification Method of AHP-EWM and the Cloud} Model. This paper introduces a classification method based on the analytic hierarchy process (AHP)-entropy weight method (EWM) and cloud model, which can classify the difficulty of rock mass fracture under $\mathrm{CO}_{2}$ phase change fracture. This method first assigns subjective and objective weights to the selected rock mass fracturing grading evaluation indicators through the analytic hierarchy process and the entropy weight method and then optimizes the weights through the Lagrange multiplier method to obtain the combined weight of each factor in the classification of rock mass fracturing in the whole classification process. After that, the cloud model of the selected classification factors is established, and the different evaluation factors of rock mass fracture ability correspond to the membership degree of different fracture grades through the digital characteristics of cloud. Finally, combined with the weight of the evaluation factor and the membership degree of each factor, the grade of the rock mass fracture ability is determined. The flowchart of the method is shown in Figure 2.

\subsubsection{Theory of Analytic Hierarchy Process (AHP).} Hierarchical analysis is a systematic analysis method proposed by American operations research scientist T. L. Saaty in the 1970s [21]. This method combines qualitative and quantitative methods to decompose complex problems into several levels and several factors and then compares each factor in pairs to obtain the weights corresponding to different problem solutions, thereby providing a theoretical basis for the choice of the best method. In the analytic hierarchy process, the selected evaluation indicators are first determined, the selected factors in pairs are compared, and they are scored according to the degree of influence of the 


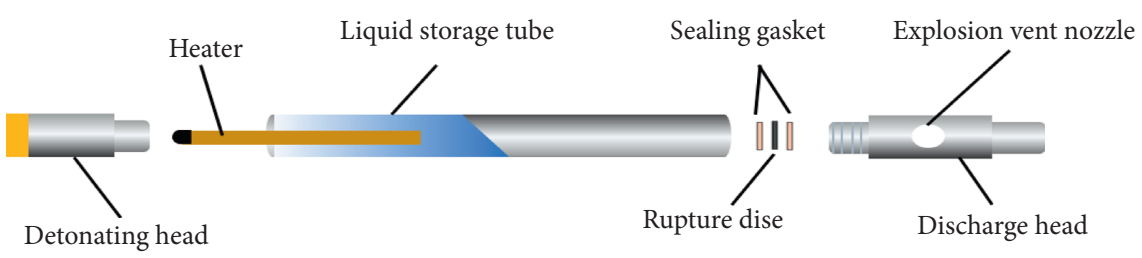

Figure 1: Structure diagram of the carbon dioxide phase change fracturing tube.

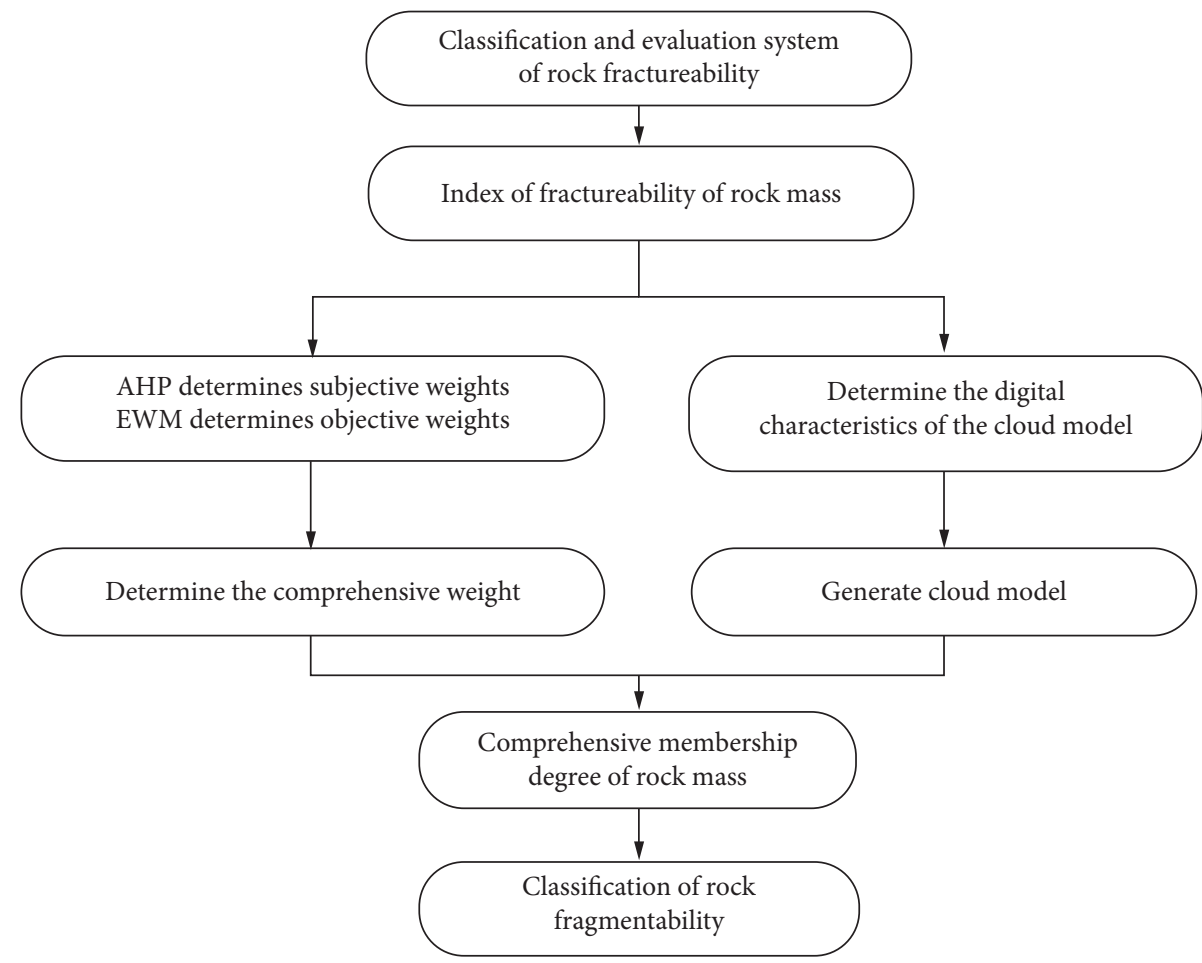

Figure 2: Flow chart of cracking classification.

comparison factor on the target factor. The scoring scale is $1-9$, as shown in Table 1 .

After scoring according to the numerical value, a judgment matrix $A=\left(a_{i j}\right)_{n \times n}$ can be constructed, where $a_{i j}$ represents the importance of the $i$-th index relative to the $j$ th index. Afterwards, the consistency test of the judgment matrix is performed to determine whether the consistency of the judgment matrix is within the recognized range, that is, whether the judgment matrix is reasonable.

The consistency of the matrix can be tested by the following formula:

$$
\begin{aligned}
\mathrm{CI} & =\frac{\lambda_{\max }-n}{n-1}, \\
\mathrm{CR} & =\frac{\mathrm{CI}}{\mathrm{RI}},
\end{aligned}
$$

where $n$ represents the order of matrix A; $\lambda_{\max }$ represents the largest eigenvalue of matrix A; and RI represents the average random consistency index, which takes a value according to the size of $n$. If CR $<0.1$, it can be considered that the judgment matrix satisfies the consistency. When the judgment matrix cannot pass the consistency test, it is necessary to reassign the degree of mutual importance between the indicators until it passes the matrix consistency test.

After checking the consistency of the matrix, the weight $\mu_{j}$ of each evaluation index can be obtained according to formula (3) of the weight value, that is, the degree of influence of each grading index with respect to the fracture ability of the rock mass.

$$
\mu_{j}=\frac{\sum_{i=1}^{n} a_{j i} / \sum_{k=1}^{n} a_{k i}(j=1,2,3, \cdots n)}{n} .
$$

2.2.2. Theory of the Entropy Weight Method (EWM). Entropy is originally derived from the definition in thermodynamics and represents the uniformity of the distribution of energy in space. At the end of the 1940s, C.E. Shannon first introduced entropy into the field of information theory and then put forward a broader concept of information entropy. Now, information theory has been successfully applied in many fields. The information entropy theory reflects the degree of information disorder and can be used to evaluate the amount of information. The more information an index carries, the greater the impact on 
TABLE 1: Numerical scales of factor contribution.

\begin{tabular}{|c|c|}
\hline Numerical scales & Meaning and explanation \\
\hline 1 & Comparing the two factors, the target factor is as important as the comparison factor \\
\hline 3 & Comparing the two factors, the target factor and the comparison factor are slightly more important \\
\hline 5 & Comparing the two factors, the target factor and the comparison factor are strongly important \\
\hline 7 & $\begin{array}{c}\text { On comparison of two factors, the target factor and the comparison factor are more strongly } \\
\text { important }\end{array}$ \\
\hline 9 & On comparison of two factors, the target factor and the comparison factor are extremely important \\
\hline $2,4,6,8$ & The intermediate values reflect an intermediate position of importance \\
\hline Reciprocals (i.e., $1,1 / 3,1 / 5, \ldots, 1 / 9$ ) & The reciprocal number reflects the reverse comparison positions of the above \\
\hline
\end{tabular}

decision making and the greater the weight. Through the information entropy theory, the objective weight of each evaluation index can be determined.

The EWM is a method of calculating the objective weight of the evaluation factor, which is different from the AHP. The first step is to set up $m$ evaluation objects and $n$ evaluation indicators when EWM is used to determine the index weight $[22,23]$. Then, the $j$-th index of the $i$-th object as $x_{i j}$ should be defined so that the data matrix $X=\left(x_{i j}\right)_{m \times n}$ about the original index of the object can be obtained.

The data in the matrix $X$ can be further normalized by the following formula to obtain a new matrix $Y=\left(y_{i j}\right)_{m \times n}$ :

$$
y_{i j}=\frac{x_{i j}-\min x_{j}}{\max x_{j}-\min x_{j}} .
$$

Afterwards, the entropy value $H_{j}$ is calculated according to each group of data in the matrix $Y=\left(\mathrm{y}_{i j}\right)_{m \times n}$, and the definition of the entropy value is shown in formula (5). After obtaining the entropy value $H_{j}$, the objective weight $\omega_{j}$ of the grading index can be obtained by formula (6):

$$
\begin{gathered}
H_{j}=-\frac{1}{\ln m} \sum_{i=1}^{m} \frac{y_{i j}}{\sum_{i=1}^{m} y_{i j}} \ln \frac{y_{i j}}{\sum_{i=1}^{m} y_{i j}}, \\
\omega_{j}=\frac{1-H_{j}}{n-\sum_{j=1}^{n} H_{j}} .
\end{gathered}
$$

The objective weight $\omega_{j}$ of each grading index is obtained by the entropy weight method. Combined with the subjective weight $\mu_{j}$ of each grading index obtained by AHP in the previous section, the final combined weight $V_{j}$ of each index is obtained by the Lagrange multiplier method. The formula of $V_{j}$ is as follows:

$$
v_{j}=\frac{\left(u_{j} \omega_{j}\right)^{0.5}}{\sum_{j=1}^{m}\left(u_{j} \omega_{j}\right)^{0.5}} .
$$

2.2.3. Theory of Cloud Model. The cloud model was first proposed by Li and Shi in 1995 [24]. It is a mathematical model to deal with the conversion of quantitative numerical value and qualitative concept uncertainty. It can effectively solve the problem of fuzzy concept quantification and has been widely used in various fields. In the grading of rock mass fracturing caused by $\mathrm{CO}_{2}$ phase change, semiquantitative and semiqualitative analysis methods are mostly used, and subjective factors are inevitably involved in the qualitative description of rock blasting characteristics. Therefore, the cloud model theory is used to analyze the complexity and fuzziness of the classification of rock mass fracturing caused by $\mathrm{CO}_{2}$ phase change, which has excellent applicability. The theoretical principles of the cloud model are as follows:

(1) Definition of cloud: suppose $X$ is a quantitative set represented by precise values, $X=\{x\}$, called domain. Any element $x$ in the set has a stable number $\mu_{c}(x)$, called the degree of membership of $x$ to $\mathrm{C}$, where $C$ is called the fuzzy set in the universe of set $X$. The distribution of the membership degree on $X$ is called the membership cloud. The membership cloud generator generates a membership degree for each element $x$ in the universe of discourse, called a cloud drop, denoted by $\left(x, \mu_{c}(x)\right)$. In the process of data processing of fuzzy sets, the degree of membership corresponding to $x$ in the universe of discourse is not fixed, but its changes will not change the overall characteristics of the membership cloud.

(2) Digital characteristics of the cloud: the core of the cloud model is to construct a cloud generator and realize the mapping between qualitative and quantitative digital feature values through the generator, reflecting the quantitative features of qualitative concepts. The cloud generator is divided into two forms: the forward and the backward cloud generators. The forward cloud generator uses the digital characteristics of the cloud: expectation $E_{x}$, entropy $E_{n}$, and hyperentropy $H_{e}$ to produce membership degrees corresponding to different values of evaluation indicators, namely, cloud drops. The backward cloud generator is opposite to the forward cloud generator. According to the distribution of $n$ cloud droplets in the cloud, the digital feature expectation $E_{x}$, entropy $E_{n}$, and hyperentropy $H_{e}$ are determined. This paper uses a forward cloud generator to generate a cloud model, and the expected curve of its subordinate cloud is approximately a normal distribution, as shown in Figure 3. Expectation $E_{x}$ is the domain value corresponding to the area centroid in the cloud model diagram, which expresses the 


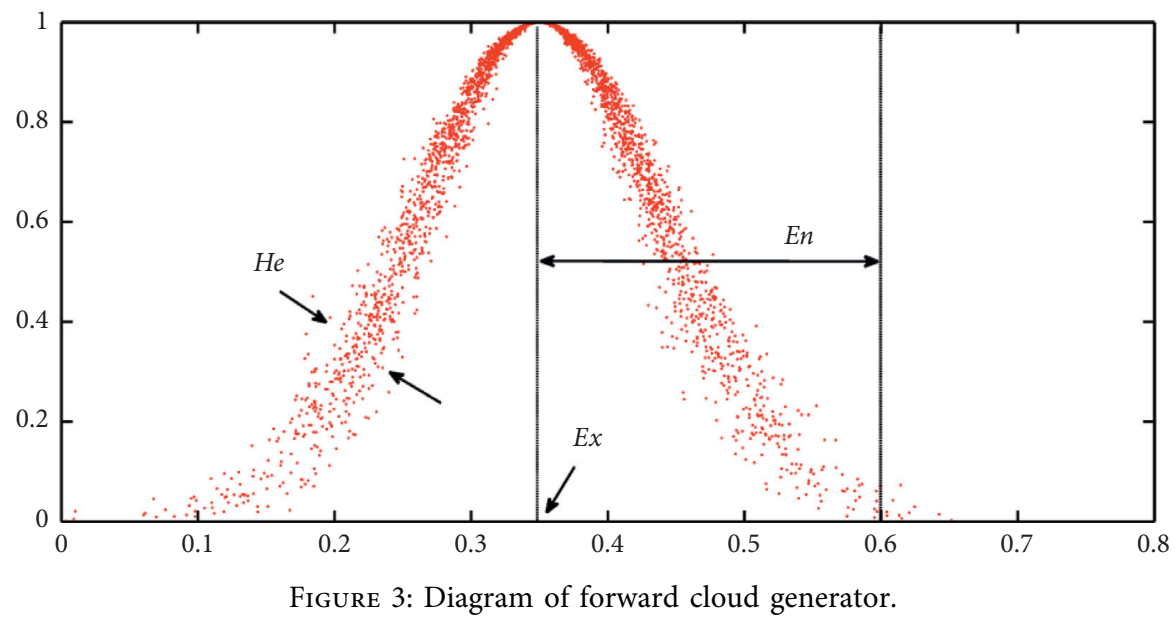

average value of the fuzzy concept. Entropy $E_{n}$ represents the range of the evaluated index and also reflects the fuzziness and randomness of the evaluated index. The smaller the $E_{n}$, the smaller the fuzziness and randomness of the evaluation index. Hyperentropy $H_{e}$ is the uncertainty measure of entropy, which describes the degree of dispersion of cloud drops in the curve.

In each grade of fracture ability, the evaluation index is a quantitative range, which has upper and lower limits $\left(C_{\mathrm{min}}\right.$, $C_{\text {max }}$ ), and the characteristic values of expectation $E_{x}$, entropy $E_{n}$, and hyperentropy $H_{e}$ can be calculated by the following formula:

$$
\left\{\begin{array}{l}
E_{x}=\left(C_{\min }+C_{\max }\right) / 2 \\
E_{n}=\left(C_{\max }-C_{\min }\right) / 2, \\
H_{e}=k
\end{array}\right.
$$

where $C_{\max }$ and $C_{\min }$ are the maximum and minimum boundary values of the corresponding grade standard, respectively, and $k$ is constant, which is taken according to the stability of the evaluation index.

The fracture ability classification of rock mass adopts a forward cloud generator, and the expected curve formed by $n$ cloud droplets generated by the forward cloud generator satisfies the normal distribution $\left(x, \mu_{c}(x)\right)$, which is defined as

$$
\mu_{C}(x)=e^{\left(-\left(x_{i}-E x\right)^{2} / 2\left(E n^{\prime}\right)^{2}\right)},
$$

where $\mu_{c}(x)$ is the degree of certainty; $x_{i}$ is the variable value; $E_{x}$ is the expectation; and $E_{n}$ is the entropy, $E_{n} \sim N\left(E_{n}, H_{e}{ }^{2}\right)$.

According to the definition of the forward cloud generator, the specific steps to generate a normal cloud model are as follows: firstly, a normal random number $x_{i}$ with expected value $E_{x}$ and standard deviation $E_{n}$ is generated. Secondly, a normal random number $E_{n}{ }^{\prime}$ with expected value $E_{n}$ and standard deviation $H_{e}$ is generated. Then, $\left(x, \mu_{c}(x)\right)$ is substituted as the cloud drop into equation (9). Afterwards, the above steps are repeated until $n$ cloud drops are generated. Finally, the forward cloud generator is used to generate a normal cloud model.

\section{Rock Mass Fracturing Classification Model Based on AHP-EWM and the Cloud Model}

3.1. Fracture Ability Classification Index. Reasonable selection of rock mass fracturing index is the prerequisite for establishing the classification model. In the process of $\mathrm{CO}_{2}$ phase transformation, the rock breaking effect is controlled by the physical and mechanical properties of the rock, the geological structure characteristics of the rock mass, and other factors. Therefore, there are many indicators that can be used to reflect the fracturing evaluation of the rock mass. This paper refers to the evaluation indexes selected by the relevant research on the explosive classification of existing rock mass and considers that the selected evaluation indexes should have the characteristics of low correlation, easy to measure, and representative. After comprehensive consideration, rock density, rock tensile strength, rock wave impedance, and rock mass integrity coefficient are selected as the classification indexes of rock mass fracture ability [25].

After selecting the evaluation index of the fracture ability of the rock mass, the classification standard of each index is further determined. According to the $\mathrm{CO}_{2}$ phase change fracturing effect in the field test and the parameter properties of the on-site rock mass, combined with the classification standard in the literature of related rock mass blasting classification, the rock mass fracturing ability is divided into 5 grades [26-28]. The fracture ability classification standard is shown in Table 2.

3.2. AHP-EWM to Determine the Weight. AHP was used to compare the importance of each parameter in Table 2, referring to relevant blastability literature and experts to evaluate the importance of each index and compare the impact of each factor on the grading of rock mass fracturing according to the evaluation criteria in Table 1. The degree of importance and the comparison result of importance are shown in Table 3. 
TABLE 2: Numerical scales of factor contribution.

\begin{tabular}{|c|c|c|c|c|c|}
\hline $\begin{array}{l}\text { Fracture ability } \\
\text { grade }\end{array}$ & $\begin{array}{l}\text { Rock mass density } \\
\left(\mathrm{g} \cdot \mathrm{cm}^{-3}\right)\end{array}$ & $\begin{array}{l}\text { Tensile strength } \\
(\mathrm{MPa})\end{array}$ & $\begin{array}{l}\text { Wave impedance of rock } \\
\quad\left(\times 10^{6} \mathrm{~kg} \cdot \mathrm{m}^{-2} \cdot \mathrm{s}^{-1}\right)\end{array}$ & $\begin{array}{l}\text { Intactness index of } \\
\text { rock mass }\end{array}$ & $\begin{array}{l}\text { Fracturing } \\
\text { description }\end{array}$ \\
\hline Grade I & $<2.5$ & $<8.0$ & $<5.0$ & $<0.05$ & Extremely easy to fracture \\
\hline Grade II & $2.5 \sim 2.8$ & $8.0 \sim 13.0$ & $5.0 \sim 8.0$ & $0.05 \sim 0.35$ & Easy to fracture \\
\hline Grade III & $2.8 \sim 3.1$ & $13.0 \sim 18.0$ & $8.0 \sim 12.0$ & $0.35 \sim 0.55$ & Medium \\
\hline Grade IV & $3.1 \sim 3.4$ & $18.0 \sim 23.0$ & $12.0 \sim 15.0$ & $0.55 \sim 0.75$ & Hard to fracture \\
\hline Grade V & $>3.4$ & $>23.0$ & $>15.0$ & $>0.75$ & Extremely hard to fracture \\
\hline
\end{tabular}

TABLE 3: Comparison of the importance of each index of rock fracture ability classification.

\begin{tabular}{lcccc}
\hline Evaluation index & Rock mass density & Tensile strength & Wave impedance of rock & Intactness index of rock mass \\
\hline Rock mass density & 1 & $1 / 5$ & $1 / 4$ & $1 / 3$ \\
Tensile strength & 5 & 1 & 2 & 3 \\
Wave impedance of rock & 4 & $1 / 2$ & 1 & 2 \\
Intactness index of rock mass & 3 & $1 / 3$ & $1 / 2$ & 1 \\
\hline
\end{tabular}

From Table 3, a judgment matrix $A=\left(a_{i j}\right)_{n \times n}$ can be obtained $\left(a_{i j}\right.$ represents the importance of the $i$-th index relative to the $j$-th index, and $n$ is the number of evaluation indexes). The maximum eigenvalue $\lambda$ of matrix $A$ is calculated by MATLAB. After that, the consistency of the judgment matrix is tested by formulas (1) and (2). The calculated $C I$ value is 0.017 , the $C R$ value is $0.019<0.1$, and the consistency of the matrix is within the recognized range, so the evaluation of grading indicators is reasonable in Table 3. And according to the calculation formula (3) of the index weight of the analytic hierarchy process, the corresponding weight of each index is obtained, as shown in Table 4.

Table 4 shows the subjective weights of the grading indicators determined by AHP. According to the AHP-EWM comprehensive weight determination method, the objective weights of the indicators need to be determined by EWM. In this regard, in combination with related literature, five typical rock mass samples that are representative in classification are selected. The index parameters of the samples are shown in Table 5.

According to Table 5, a data matrix $X=\left(x_{i j}\right)_{m \times n}$ can be constructed $\left(x_{i j}\right.$ represents the $j$-th index value of the $i$-th sample, $m$ is the number of samples, and $n$ is the number of evaluation indexes). According to formula (4), the matrix $X$ is normalized to obtain the matrix $Y=\left(y_{i j}\right)_{m \times n}$. Then, the entropy value and weight of each evaluation index are calculated according to formulas (5) and (6), as shown in Table 6 .

According to the weights of each index in Tables 4 and 6, combined with formula (7), the final combined weight of each index is obtained, as shown in Table 7 .

3.3. Building a Cloud Model. According to the rock mass fracture ability classification evaluation index and the cloud digital feature expectation $E_{x}$, entropy $E_{n}$, and hyperentropy $H_{e}$ calculation methods, the cloud digital feature calculation method of the fracture ability classification evaluation index can be obtained, as shown in Table 8. Among them, the superentropy $H_{e}$ is 0.01 . Combining the grading indexes and standards in Table 2, the cloud digital characteristics corresponding to the grading evaluation indexes of rock mass fracturing under $\mathrm{CO}_{2}$ phase change fracturing can be obtained, as shown in Table 9.

The cloud digital features of the evaluation indexes in Table 9 are input into the forward cloud generator to generate the cloud model of the membership degree corresponding to different indexes of rock mass crackability, as shown in Figure 4.

When evaluating the fracturing grade of a rock mass in a certain area, it is only needed to input the measured data of each grading index of the rock mass into the forward cloud generator, and the membership degree of each index of the rock mass for the crackability of $\mathrm{I} \sim \mathrm{V}$ grades can be obtained.

Then, combined with the weight of each evaluation index in Table 7, the comprehensive membership degree of the rock mass with respect to the fracture ability of grades $\mathrm{I} \sim \mathrm{V}$ can be obtained. The calculation formula is as shown in the following formula:

$$
U_{i}=\sum_{j=1}^{m} \mu_{i j}(x) v_{j},
$$

where $U_{i}$ is the comprehensive membership degree of the rock mass to the $i$-th grade; $\mu_{i j}(x)$ is the membership degree of the rock mass to the $j$-th index in the $i$-th grade; and $v_{j}$ is the weight of the corresponding evaluation index.

Finally, the fracturing grade of the rock mass can be determined by comparing the magnitude of each $U_{i}$ value.

$$
i=\max \left\{U_{i} \mid i=1,2,3,4,5\right\},
$$

where the value of $i$ is the fracturing grade corresponding to the evaluated rock mass $(1,2,3,4$, and 5, respectively, represent Grade I, II, III, IV, and V).

\section{Engineering Application Analysis}

4.1. Research Area. In order to apply this classification method to engineering practice, the $\mathrm{K} 6+000-\mathrm{K} 8+000$ and $\mathrm{K} 13+000-\mathrm{K} 15+393$ sections of a reconstruction 
TABLE 4: Weight obtained by AHP.

\begin{tabular}{lcccc}
\hline Grading index & $\begin{array}{c}\text { Rock mass density } \\
\left(\mathrm{g} \cdot \mathrm{cm}^{-3}\right)\end{array}$ & $\begin{array}{c}\text { Tensile } \\
\text { strength }(\mathrm{MPa})\end{array}$ & $\begin{array}{c}\text { Wave impedance of rock } \\
\left(\times 10^{6} \mathrm{~kg} \cdot \mathrm{m}^{-2} \cdot \mathrm{s}^{-1}\right)\end{array}$ & $\begin{array}{c}\text { Intactness index of rock } \\
\text { mass }\end{array}$ \\
\hline Weight & 0.0729 & 0.4728 & 0.2844 & 0.1699 \\
\hline
\end{tabular}

Table 5: Parameters of the sample rock mass.

\begin{tabular}{lcccc}
\hline $\begin{array}{l}\text { Number of the rock } \\
\text { mass sample }\end{array}$ & $\begin{array}{c}\text { Rock mass density } \\
\left(\mathrm{g} \cdot \mathrm{cm}^{-3}\right)\end{array}$ & $\begin{array}{c}\text { Tensile strength } \\
(\mathrm{MPa})\end{array}$ & $\begin{array}{c}\text { Wave impedance of rock } \\
\left(\times 10^{6} \mathrm{~kg} \cdot \mathrm{m}^{-2} \cdot \mathrm{s}^{-1}\right)\end{array}$ & $\begin{array}{c}\text { Intactness index of rock } \\
\text { mass }\end{array}$ \\
\hline 1 & 1.5 & 12 & 3 & 0.04 \\
2 & 2.7 & 10 & 1 & 0.2 \\
3 & 3.0 & 15 & 13 & 0.4 \\
4 & 3.2 & 19 & 27 & 0.6 \\
5 & 3.8 & 24 & 0.8 \\
\hline
\end{tabular}

TABLE 6: Entropy and weight obtained by EWM.

\begin{tabular}{lcccc}
\hline Grading index & $\begin{array}{c}\text { Rock mass density } \\
\left(\mathrm{g} \cdot \mathrm{cm}^{-3}\right)\end{array}$ & $\begin{array}{c}\text { Tensile } \\
\text { strength }(\mathrm{MPa})\end{array}$ & $\begin{array}{c}\text { Wave impedance of rock } \\
\left(\times 10^{6} \mathrm{~kg} \cdot \mathrm{m}^{-2} \cdot \mathrm{s}^{-1}\right)\end{array}$ & $\begin{array}{c}\text { Intactness index of rock } \\
\text { mass }\end{array}$ \\
\hline Entropy & 0.8438 & 0.7417 & 0.7296 & 0.7822 \\
Weight & 0.1730 & 0.2861 & 0.2995 & 0.2412 \\
\hline
\end{tabular}

TABLE 7: Comprehensive weight of rock mass fracturing evaluation index.

\begin{tabular}{lcccc}
\hline Grading index & $\begin{array}{c}\text { Rock mass density } \\
\left(\mathrm{g} \cdot \mathrm{cm}^{-3}\right)\end{array}$ & $\begin{array}{c}\text { Tensile } \\
\text { strength }(\mathrm{MPa})\end{array}$ & $\begin{array}{c}\text { Wave impedance of rock } \\
\left(\times 10^{6} \mathrm{~kg} \cdot \mathrm{m}^{-2} \cdot \mathrm{s}^{-1}\right)\end{array}$ & $\begin{array}{c}\text { Intactness index of rock } \\
\text { mass }\end{array}$ \\
\hline Weight & 0.1154 & 0.3774 & 0.2995 & 0.2077 \\
\hline
\end{tabular}

TABLE 8: Calculation method about digital characteristics of the cloud.

\begin{tabular}{lcccc}
\hline Fracture ability grade & Range of evaluation indicators & Expectation $E_{x}$ & Entropy $E_{n}$ & Hyperentropy $H_{e}$ \\
\hline Grade I & $(0, \mathrm{a})$ & $E_{\mathrm{x} 1}=(0+a) / 2$ & $E_{\mathrm{n} 1}=(a-0) / 6$ & 0.01 \\
Grade II & $(\mathrm{a}, \mathrm{b})$ & $E_{\mathrm{x} 2}=(a+b) / 2$ & $E_{\mathrm{n} 2}=(b-a) / 6$ & 0.01 \\
Grade III & $(\mathrm{b}, \mathrm{c})$ & $E_{\mathrm{x} 3}=(b+c) / 2$ & $E_{\mathrm{n} 3}=(c-b) / 6$ & 0.01 \\
Grade IV & $(\mathrm{c}, \mathrm{d})$ & $E_{\mathrm{x} 4}=(c+d) / 2$ & $E_{\mathrm{n} 4}=(d-c) / 6$ & 0.01 \\
Grade V & $(\mathrm{d},+\infty)$ & $E_{\mathrm{x} 5}=d$ & $E_{\mathrm{n} 5}=E_{\mathrm{n} 4}$ & 0.01 \\
\hline
\end{tabular}

project in Milin County, Linzhi City, Tibet, are taken as the research objects of rock mass fracturing classification. These two sections belong to the piedmont colluvial slope, and the strata are dominated by quaternary loose colluvial layer breccia and intercalated rocks. The main mineral composition of strata rock mass is feldspar, quartz, and hornblende, which have high compressive strength and belong to hard rock. Commonly used mechanical excavation methods cannot effectively destroy the rock mass, so it is planned to use $\mathrm{CO}_{2}$ phase change fracturing technology to break the rock. According to the strength, the rocks in this project area can be divided into three types: feldspar quartz sandstone (A), feldspar quartz fine sandstone (B), and diorite $(\mathrm{C})$. In order to determine the crackability grades of the three types of rock masses in the construction area of the project and to provide theoretical guidance for the actual fracturing project, firstly, the three types of rock masses in the construction area were sampled. The rock samples are shown in Figure 5. Subsequently, an on-site investigation of the engineering geological conditions of the area was carried out; combined with the indoor test of the rock samples obtained in the engineering area, the parameters of the fracturing evaluation index of the rock mass in the engineering area were obtained, as shown in Table 10.

4.2. Research Area Analysis of Rock Fracture Ability in the Engineering Area. By inputting the data from Table 10 into the forward cloud model, the membership degree of each evaluation index of nine rock mass samples in $\mathrm{I} \sim \mathrm{V}$ grade rock masses can be obtained. According to Table 4, the comprehensive weights of rock density, tensile strength, wave impedance of rock, and intactness index of rock mass are $0.1154,0.3774,0.2995$, and 0.2077 , respectively. According to the membership degree calculation formula 
TABLE 9: Cloud digital characteristics of fracture ability evaluation index.

\begin{tabular}{|c|c|c|c|c|c|c|}
\hline \multirow{2}{*}{ Fracture ability grade } & \multicolumn{3}{|c|}{ Rock mass density $\left(\mathrm{g} \cdot \mathrm{cm}^{-3}\right)$} & \multicolumn{3}{|c|}{ Tensile strength $(\mathrm{MPa})$} \\
\hline & $E_{\mathrm{x}}$ & $E_{\mathrm{n}}$ & $H_{\mathrm{e}}$ & $E_{\mathrm{x}}$ & $E_{\mathrm{n}}$ & $H_{\mathrm{e}}$ \\
\hline Grade I & 1.25 & 0.42 & 0.01 & 4.00 & 1.33 & 0.01 \\
\hline Grade II & 2.65 & 0.05 & 0.01 & 10.50 & 0.83 & 0.01 \\
\hline Grade III & 2.95 & 0.05 & 0.01 & 15.50 & 0.83 & 0.01 \\
\hline Grade IV & 3.25 & 0.05 & 0.01 & 20.50 & 0.83 & 0.01 \\
\hline Grade V & 3.40 & 0.05 & 0.01 & 23.00 & 0.83 & 0.01 \\
\hline \multirow{2}{*}{ Fracture ability grade } & \multicolumn{3}{|c|}{ Wave impedance of rock $\left(\times 10^{6} \mathrm{~kg} \cdot \mathrm{m}^{-2} \cdot \mathrm{s}^{-1}\right)$} & \multicolumn{3}{|c|}{ Intactness index of rock mass } \\
\hline & $E_{\mathrm{x}}$ & $E_{\mathrm{n}}$ & $H_{\mathrm{e}}$ & $E_{\mathrm{x}}$ & $E_{\mathrm{n}}$ & $H_{\mathrm{e}}$ \\
\hline Grade I & 2.50 & 0.83 & 0.01 & 0.025 & 0.008 & 0.01 \\
\hline Grade II & 6.50 & 0.50 & 0.01 & 0.20 & 0.05 & 0.01 \\
\hline Grade III & 10.00 & 0.67 & 0.01 & 0.45 & 0.033 & 0.01 \\
\hline Grade IV & 13.50 & 0.50 & 0.01 & 0.65 & 0.033 & 0.01 \\
\hline Grade V & 15.00 & 0.50 & 0.01 & 0.75 & 0.033 & 0.01 \\
\hline
\end{tabular}

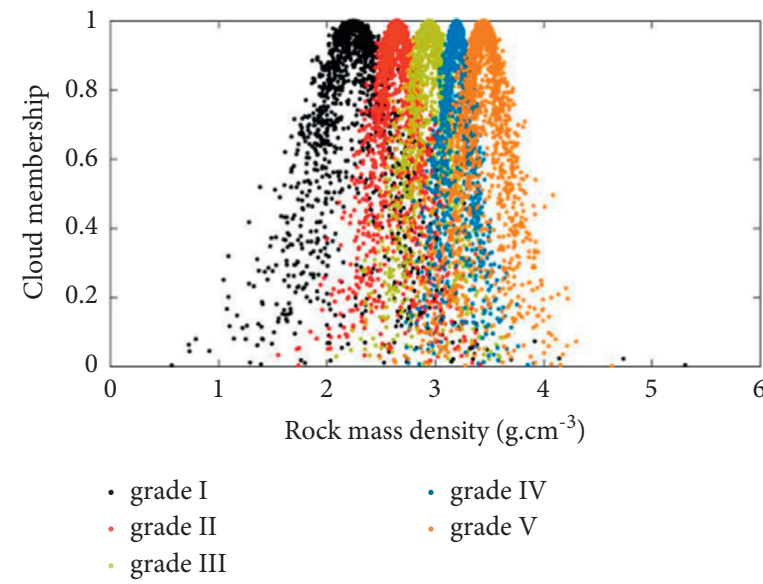

(a)

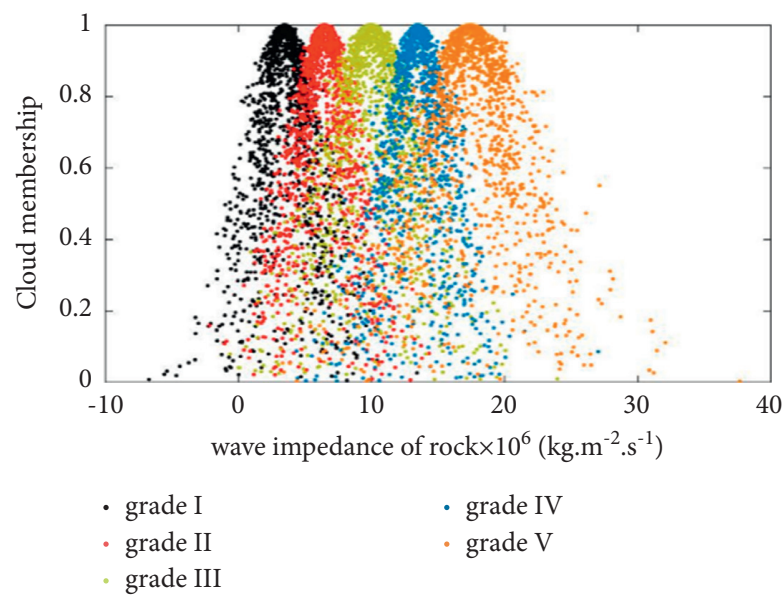

(c)

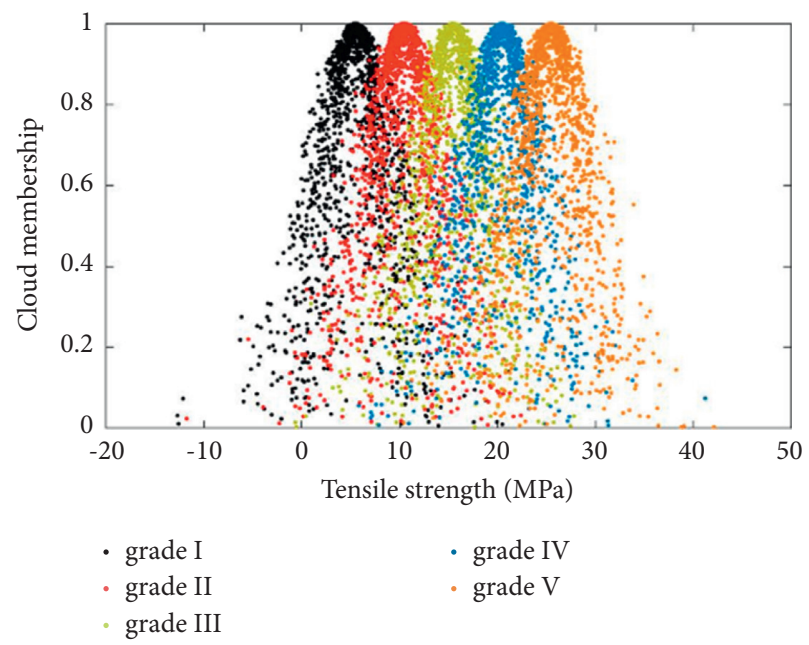

(b)

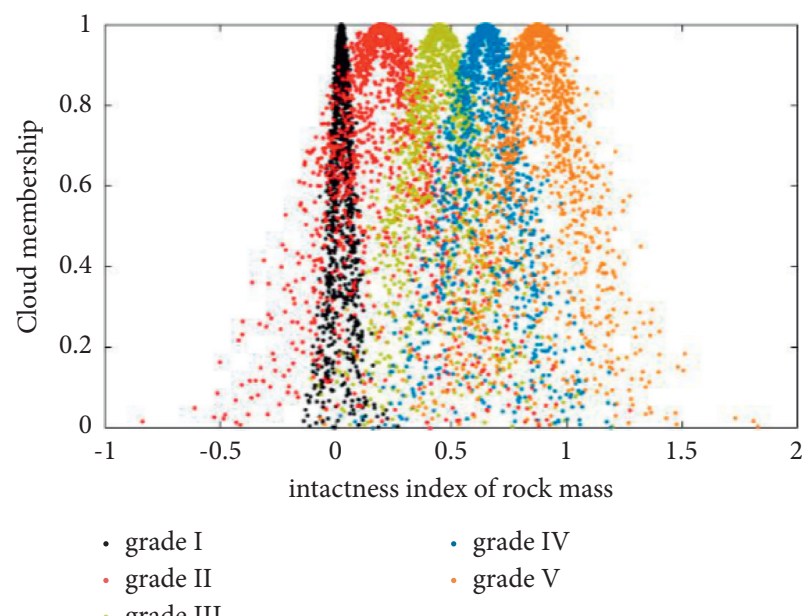

(d)

Figure 4: Cloud model diagram of different graded indexes of rock mass fracturing. (a) Rock mass density. (b) Tensile strength. (c) Wave impedance of rock. (d) Intactness index of rock mass. 


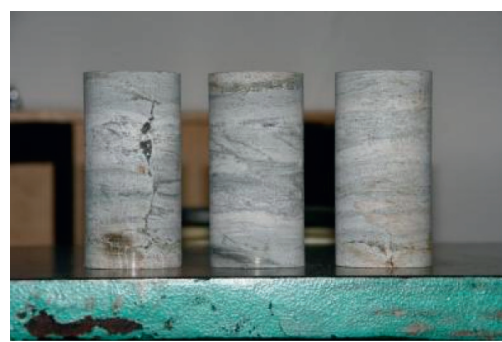

(a)

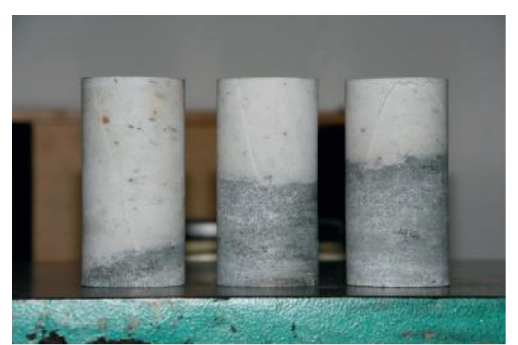

(b)

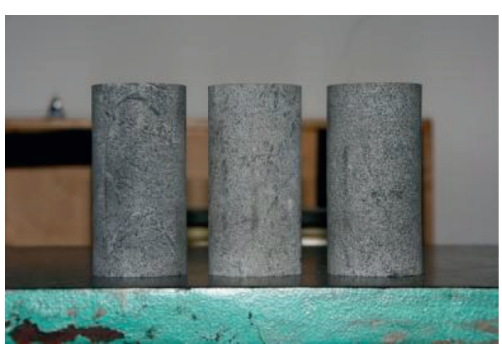

(c)

FIgURE 5: Rock samples in the engineering area. (a) Rock sample A, (b) rock sample B, and (c) rock sample C.

TABle 10: Parameters of rock samples in the engineering area.

\begin{tabular}{|c|c|c|c|c|}
\hline Rock samples & $\begin{array}{l}\text { Rock mass density } \\
\left(\mathrm{g} \cdot \mathrm{cm}^{-3}\right)\end{array}$ & $\begin{array}{c}\text { Tensile } \\
\text { strength }(\mathrm{MPa}) \\
\end{array}$ & $\begin{array}{l}\text { Wave impedance of rock } \\
\quad\left(\times 10^{6} \mathrm{~kg} \mathrm{~m}^{-2} \mathrm{~s}^{-1}\right)\end{array}$ & $\begin{array}{c}\text { Intactness index of rock } \\
\text { mass }\end{array}$ \\
\hline$A_{1}$ & 2.64 & 9.8 & 8.950 & \multirow{3}{*}{0.786} \\
\hline $\mathrm{A}_{2}$ & 2.68 & 9.6 & 8.788 & \\
\hline $\mathrm{A}_{3}$ & 2.65 & 10.1 & 8.984 & \\
\hline $\mathrm{B}_{1}$ & 2.73 & 14.2 & 10.303 & \multirow{3}{*}{0.636} \\
\hline $\mathrm{B}_{2}$ & 2.75 & 14.8 & 11.226 & \\
\hline $\mathrm{B}_{3}$ & 2.71 & 15.1 & 11.062 & \\
\hline $\mathrm{C}_{1}$ & 3.06 & 22.4 & 13.020 & \multirow{3}{*}{0.732} \\
\hline $\mathrm{C}_{2}$ & 3.05 & 23.8 & 12.978 & \\
\hline $\mathrm{C}_{3}$ & 3.06 & 23.6 & 12.491 & \\
\hline
\end{tabular}

TABLE 11: Fracture ability classification results of rock mass.

\begin{tabular}{|c|c|c|c|c|c|c|}
\hline \multirow{2}{*}{ Rock samples } & \multicolumn{5}{|c|}{ Comprehensive membership } & \multirow{2}{*}{ Fracture ability grade } \\
\hline & $\mathrm{U}_{1}$ & $\mathrm{U}_{2}$ & $\mathrm{U}_{3}$ & $\mathrm{U}_{4}$ & $\mathrm{U}_{5}$ & \\
\hline$A_{1}$ & 0.3357 & 0.6772 & 0.5012 & 0.3306 & 0.3654 & Grade II \\
\hline $\mathrm{A}_{2}$ & 0.2623 & 0.5969 & 0.4351 & 0.3439 & 0.2972 & Grade II \\
\hline$A_{3}$ & 0.3173 & 0.6561 & 0.4614 & 0.4331 & 0.2941 & Grade II \\
\hline $\mathrm{B}_{1}$ & 0.0989 & 0.4975 & 0.7171 & 0.5158 & 0.2104 & Grade III \\
\hline $\mathrm{B}_{2}$ & 0.1474 & 0.3019 & 0.7991 & 0.3841 & 0.2017 & Grade III \\
\hline $\mathrm{B}_{3}$ & 0.1423 & 0.4314 & 0.8634 & 0.5538 & 0.2959 & Grade III \\
\hline $\mathrm{C}_{1}$ & 0.0501 & 0.1568 & 0.5479 & 0.8991 & 0.5712 & Grade IV \\
\hline $\mathrm{C}_{2}$ & 0.1478 & 0.1659 & 0.6010 & 0.8636 & 0.6599 & Grade IV \\
\hline $\mathrm{C}_{3}$ & 0.1087 & 0.2003 & 0.3251 & 0.7490 & 0.5879 & Grade IV \\
\hline
\end{tabular}

(10), the comprehensive membership degree of each rock mass sample for different grades can be obtained, and the results are shown in Table 11.

From the membership degree of different rock samples in Table 11, the fracture ability grades of the three types of rock masses in the engineering area are as follows: the grade of the fracture ability of rock mass $\mathrm{A}(\mathrm{A} 1 \sim \mathrm{A} 3)$ is grade II, that of rock mass $B(B 1 \sim B 3)$ is grade III, and that of rock mass $\mathrm{C}(\mathrm{C} 1 \sim \mathrm{C} 3)$ is grade $\mathrm{IV}$. The rock mass in the construction area is generally in the range of easy to fracture to hard to fracture.

Through AHP-EWM and the cloud model method, the $\mathrm{CO}_{2}$ phase transformation rock breaking fracture ability classification of the rock in the engineering area is carried out, the rock mass parameters of the engineering area are scientifically and reliably analyzed, and the actual blasting work guidance is provided for the regional blasting construction work.

\section{Conclusions}

This paper puts forward the concept of rock mass fracturing under the action of $\mathrm{CO}_{2}$ phase change rock breaking. On the basis of the rock mass blastability classification theory, a $\mathrm{CO}_{2}$ phase change fracturing based on AHP-EWM and the cloud model is proposed, and the classification method is applied to a reconstruction project in Tibet. The main conclusions obtained are as follows:

(1) Based on the classification theory of rock mass blastability, AHP-EWM and cloud model classification for rock mass fracturing were proposed, which can effectively classify and evaluate rock mass fracturing. Moreover, the method is simple and easy to implement, overcomes the shortcomings of the traditional grading method's fixed evaluation mode, and has strong applicability. 
(2) When using AHP-EWM and the cloud model to classify the rock mass, the classification evaluation index of rock mass fracture ability is determined first. The subjective weight and objective weight are given to the selected evaluation indexes by AHP and EWM, and the combined weight is obtained by optimizing the weights of the two by the Lagrange multiplier method. Then, the cloud model of evaluation index is established, and the membership degree of different fracture grades corresponding to different grade evaluation indexes of rock mass fracture ability is determined by the digital characteristics of the cloud. Finally, different final membership degrees are obtained by using the product of the weight of evaluation index and the membership degree of each index.

(3) The grading evaluation method is applied to the rock mass in a reconstruction project in Milin County, Tibet. The rock mass in the area is classified in terms of fracture ability. It is obtained that the three main rock masses in the area are fracturing relative to each grade. Among the three types of rock mass, feldspar quartz sandstone is divided into grade II, which is easy to fracture rock mass; feldspar quartz fine sandstone is divided into grade III, which belongs to medium hard to fracturing rock mass; diorite is divided into grade IV, which is difficult to the fracture rock mass. This method provides scientific guidance for engineering construction by classifying the crackability of the rock mass.

\section{Data Availability}

All data, models, and codes generated or used during the study appear in the submitted article.

\section{Conflicts of Interest}

The authors declare that they have no conflicts of interest.

\section{References}

[1] D. R. Schooler, The Use of Carbon Dioxide for Dislodging Coal in Mines, curtis laws wilson library, MO USA, 1944.

[2] R. Holmberg and T. White, "Cardox system brings benefits in the mining of large coal," International Journal of Rock Mechanics and Mining Science \& Geomechanics Abstracts, vol. 32, no. 5, p. 231, 1995.

[3] J. Xia, B. Dou, H. Tian, J. Zheng, G. Cui, and M. Kashif, "Research on initiation of carbon dioxide fracturing pipe using the liquid carbon dioxide phase-transition blasting technology," Energies, vol. 14, no. 3, p. 521, 2021.

[4] X. Liu, Z. Wang, D. Song, X. He, and T. Yang, "Variations in surface fractal characteristics of coal subjected to liquid CO 2 phase change fracturing," International Journal of Energy Research, vol. 44, no. 11, pp. 8740-8753, 2020.

[5] Z. Liao, X. Liu, D. Song et al., "Micro-structural damage to coal induced by liquid CO2 phase change fracturing," Natural Resources Research, vol. 30, pp. 1613-1627, 2021.

[6] H. Wang, Z. Cheng, Q. Zou et al., "Elimination of coal and gas outburst risk of an outburst-prone coal seam using controllable liquid $\mathrm{CO} 2$ phase transition fracturing," Fuel, vol. 284, Article ID 119091, 2021.

[7] Q.-Y. Li, G. Chen, D.-Y. Luo, H.-P. Ma, and Y. Liu, "An experimental study of a novel liquid carbon dioxide rockbreaking technology," International Journal of Rock Mechanics and Mining Sciences, vol. 128, Article ID 104244, 2020.

[8] C. P. Wen and R. Li, "Attribute measurement model and application for classification of rock blastability," Engineering blasting, no. 03, pp. 14-17, 2007.

[9] T. Y. Wu, N. Jiang, C. B. Zhou, X. D. Luo, H. B. Li, and Y. Q. Zhang, "Experimental and numerical investigations on damage assessment of high-density polyethylene pipe subjected to blast loads," Engineering Failure Analysis, vol. 131, Article ID 105856, 2022.

[10] N. Jiang, B. Zhu, C. B. Zhou et al., "Blasting vibration effect on the buried pipeline: a brief overview," Engineering Failure Analysis, vol. 129, Article ID 105709, 2021.

[11] S. Xiao, K. Li, X. Ding, and T. Liu, "Rock mass blastability classification using fuzzy pattern recognition and the combination weight method," Mathematical Problems in Engineering, vol. 2015, no. 12, 11 pages, Article ID 724619, 2015.

[12] X. H. Ding, W. J. Yuan, Z. Jie et al., "Classification and identification of rock blastability in open-pit minebased on comprehensive weighted cloud model," Coal Science and Technology, vol. 47, no. 10, pp. 96-101, 2019.

[13] S. Wu, S. Yang, and Q. Wang, "Classification of open pit iron mine rock mass blastability based on concept lattice and rough set," Geotechnical \& Geological Engineering, vol. 38, no. 1, pp. 449-458, 2020.

[14] A. Alipour, M. Mokharian, and S. Chehreghani, "An application of fuzzy sets to the blastability index (BI) used in rock engineering," Periodica Polytechnica: Civil Engineering, vol. 62 , no. 3, pp. 1-10, 2018.

[15] N. Jiang, Y. Q. Zhang, T. Y. Wu, Y. K. Yao, and X. D. Luo, "Determination of blasting vibration safety criterion for HDPE pipeline using vibration and strain data in a coastal metro line," Sensors, vol. 21, p. 7252, 2021.

[16] G. Y. Zhao, M. L. Gong, W. Z. Liang, and C. S. Hong, "Rock mass blastability classification using the combination of PSM and CM," Mining and metallurgy engineering, vol. 36, no. 03, pp. 21-25, 2016.

[17] T. Zhou, J. H. Hu, Y. Kuang, and R. D. Huang, "Improved rock engineering system (RES)-Multidimensional cloud evaluation model and its application to the rock mass blastability," IEEE Access, vol. 7, no. 99, pp. 1100305-100317, 2019.

[18] C.-1. Gao, S.-c. Li, J. Wang, L.-p. Li, and P. Lin, “The risk assessment of tunnels based on grey correlation and entropy weight method," Geotechnical \& Geological Engineering, vol. 36, no. 3, pp. 1621-1631, 2018.

[19] T. J. Tao, P. Huang, J. Li, J. Zhou, and H. Yu, "Blastability classification of fractured rock mass based on weighted clustering analysis," Chemical Engineering Transactions (CET Journal), vol. 62, pp. 469-474, 2017.

[20] Y. Zheng, H. Zhong, Y. Fang, W. Zhang, K. Liu, and J. Fang, "Rockburst prediction model based on entropy weight integrated with grey relational BP neural network," Advances in Civil Engineering, vol. 2019, Article ID 3453614, 8 pages, 2019.

[21] K. Zhao, N. Jiang, C. B. Zhou, H. B. Li, B. Zhu et al., "Dynamic behavior and failure of buried gas pipeline considering the pipe connection form subjected to blasting seismic waves," Thin-Walled Structures, vol. 170, Article ID 108495, 2022.

[22] A. Xl, L. A. Wei, A. Lz, and X. Guo, "Risk assessment for longdistance gas pipelines in coal mine gobs based on structure 
entropy weight method and multi-step backward cloud transformation algorithm based on sampling with replacement," Journal of Cleaner Production, vol. 227, pp. 218-228, 2019.

[23] H. Xu, C. Ma, J. Lian, K. Xu, and E. Chaima, "Urban flooding risk assessment based on an integrated k-means cluster algorithm and improved entropy weight method in the region of Haikou, China," Journal of Hydrology, vol. 563, pp. 975986, 2018.

[24] D. Y. Li and X. M. Shi, "Membership clouds and membership cloud generators," Computer research and development, vol. 32, no. 06, pp. 15-20, 1995.

[25] S. J. Yu, M. Y. Xin, S. L. Mao et al., "Correlation analysis of rock mass explosibility index," Journal of rock mechanics and engineering, vol. 24, no. 003, pp. 468-473, 2005.

[26] S. J. Li, Y. P. Zhang, H. Z. Zhu, and J. J. Xuan, "Blasting classification of rock mass based on clustering analysis of comprehensive weight," Engineering blasting, vol. 21, no. 03, pp. 18-22, 2015.

[27] B. Zhu, N. Jiang, C. Zhou, X. Luo, Y. Yao, and T. Wu, "Dynamic failure behavior of buried cast iron gas pipeline with local external corrosion subjected to blasting vibration," Journal of Natural Gas Science and Engineering, vol. 88, Article ID 103803, 2021.

[28] N. Jiang, B. Zhu, X. He, C. Zhou, X. Luo, and T. Wu, "Safety assessment of buried pressurized gas pipelines subject to blasting vibrations induced by metro foundation pit excavation," Tunnelling and Underground Space Technology, vol. 102, Article ID 103448, 2020. 